\title{
Systemic embolisation
}

\author{
D Richardson, $\mathrm{CH}$ Jones
}

A 71-year-old woman presented with acute onset of painful paraesthesia in both legs. She gave a 12-month history of paroxysmal palpitations, but there was no history of chest pain, dyspnoea or intermittent claudication. Medical history included pulmonary tuberculosis aged 34 and osteoarthritis treated with coproxamol. She took no other medication. On examination femoral and popliteal pulses were absent. Both legs were pale and cold. There was bilateral paraesthesia with motor weakness grade 4/5. Urgent bilateral femoral embolectomy was undertaken. Postoperatively, a transthoracic echocardiogram was normal. A transoesophageal echo is illustrated in figure 1. Embolus histology is shown in figure 2.

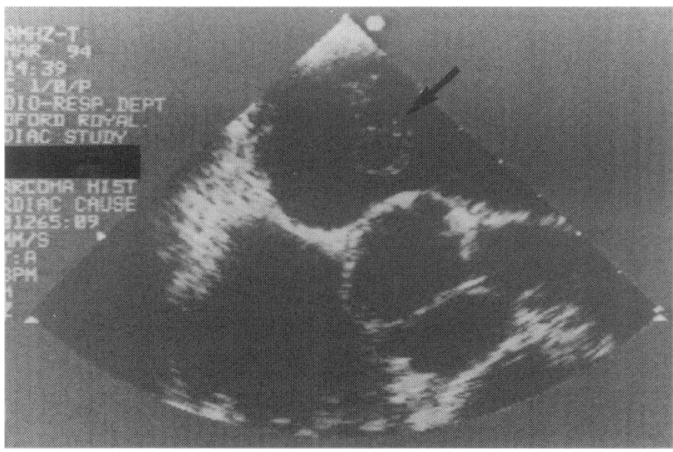

Figure 1 Transoesophageal echo

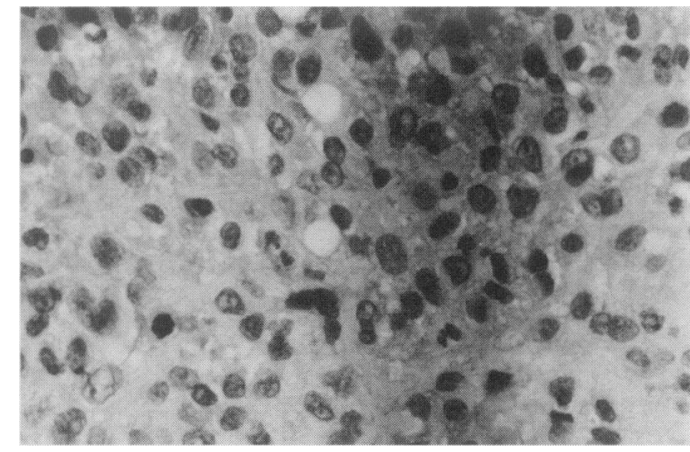

Figure 2 Embolus histology

\section{Department of Renal Medicine, St James's University Hospital, Leeds LS9 7TF, UK \\ D Richardson \\ $\mathrm{CH}$ Jones}

Accepted 3 January 1996

\section{Questions}

1 What is the differential diagnosis of acute bilateral lower limb paraesthesia?

2 What are the likely sources of the embolus?

3 What does the echocardiogram show?

4 What is unusual about the embolus histology?

5 How else can such lesions present? 


\section{Answers}

QUESTION 1

The differential diagnosis is given in box 1 . The association of painful paraesthesia, motor weakness and absent leg pulses make arterial occlusion by embolus the most likely diagnosis.

\section{QUESTION 2}

The most likely source of the embolus is one of the following:

- left atrium (atrial fibrillation, mitral valve disease)

- left ventricle (mural thrombus, left ventricular aneurysm)

- paradoxical embolus through a patent right to left communication

- aorta (atheroemboli)

\section{QUESTION 3}

There is a pedunculated mass lesion projecting into the left atrium (figure 1, arrow). Possible causes include thrombus, massive vegetation, benign tumour (atrial myxoma) and malignant tumour, either primary (leiomyosarcoma) or secondary (from mediastinum or vena cava).

Transthoracic echocardiogram may miss left atrial lesions. Transoesophageal echocardiography has been recommended for 'cardiac screening' of patients presenting with arterial embolisation. ${ }^{1}$ The pedunculated nature of the lesion suggests a primary left atrial neoplasm. This was confirmed on thoracic CT scan.

\section{QUESTION 4}

Embolus histology usually reveals thrombus, which consists of alternating layers of platelets and acellular fibrin. In this case, histology shows pleomorphic cells with scattered mitotic figures. Immunocytochemistry confirmed this

1 Dressler FA, Labovitz AJ. Systemic arterial emboli and cardiac masses. Assessment with transesophageal echocardiography. Cardiol Clin 1993; 11: 447-60.

2 Nguyen KT, Mak K, Sanfilippo AJ, Rosen WS, Cheeseman FD. Primary left atrial leiomyosarcoma simulating pulmonary thromboembolism. Can Assoc Radiol f 1994; 45: 48-51.

3 Antunes MJ, Vanderdonck KM, Andrade CM, Rebelo IS Primary cardiac leiomyosarcomas. Ann Thorac Surg 1991; 51: $999-1001$.

4 Donovan VM, Summer W, Hutchins GM. Left atrial leiomyosarcoma: manifestation as unexplained pulmonary vascular disease. Arch Intern Med 1982; 142: 1923-5.

\section{Differential diagnosis}

- acute ischaemia (embolus, rupture of aortic aneurysm, dissection of aorta)

- acute cord compression (spinal cord neoplasm, disc/vertebral lesions, epidural abscess including tuberculous)

- acute transverse myelitis (viral, multiple sclerosis, syphilis, anterior spinal artery occlusion)

Box 1

to be a leiomyosarcoma. Embolus histology is clearly of importance and in this case allowed a histological diagnosis of a primary tumour to be made without further invasive procedures.

\section{QUESTION 5}

Primary cardiac leiomyosarcoma is rare. Presentation with symptoms and signs of pulmonary embolisation, ${ }^{1,2}$ pulmonary hypertension, ${ }^{3}$ left ventricular outflow obstruction, ${ }^{4}$ recurrent pulmonary oedema' ${ }^{5}$ and 'mixed mitral valve

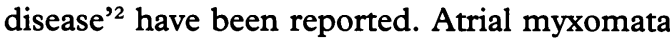
can also present with peripheral embolisation or signs and symptoms of infective endocarditis. The prognosis of left atrial leiomyosarcoma is poor, with survival limited to months regardless of treatment.

\section{Final diagnosis}

Primary cardiac leiomyosarcoma with bilateral femoral embolisation.

Keywords: cardiac leiomyosarcoma, femoral embolisation

5 Fox JP, Freitas E, McGiffin DC, Firouz-Abadi AA, Wes MJ. Primary leiomyosarcoma of the heart: a rare cause of obstruction of the left ventricular outflow tract. Aust NZ Med 1991; 21: 881-3.

6 Fyfe AI, Huckell VF, Burr LH, Stonier PM. Leiomyosarcoma of the left atrium: case report and review of the literature. Can f Cardiol 1991; 7: 193-6. 